\title{
Entrepreneurship and creation of new business: Key factors of Brazilian entrepreneurial ecosystem
}

\author{
Lucas Lopes Ferreira de Souza ${ }^{1}$, Felipe Gerhard ${ }^{2}$, Renata Lèbre La Rovere³, Samuel Façanha Câmara
}

${ }^{1}$ Universidade Estadual do Ceará- e-mail: lucaslfsouza@ hotmail.com

2 Universidade Estadual do Ceará - e-mail: felipegerhard.rns@gmail.com

${ }^{3}$ Universidade Federal do Rio de Janeiro - e-mail: relarovere@gmail.com

Universidade Estadual do Ceará - e-mail: samuel.camara@uece.br

\section{KEYWORDS}

Entrepreneurship

Information and

Communication Technologies

Brazilian entrepreneurial

ecosystem.

Received 13.05.2016

Revised 23.05.2016

Accepted 23.05. 2016

ISSN 1980-4431

Double blind review

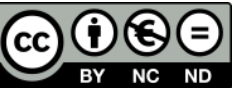

\section{ABSTRACT}

This article aims to analyze the profile of Brazilian entrepreneurs and the factors that shape the entrepreneurial ecosystem in the country. A survey was conducted with 76 Brazilian entrepreneurs from the ICT sector, which was chosen because of its high growth rates. The research was developed in the context of a joint project called Entrepreneurship as a Growth Driver that involves universities from five countries: Italy, Brazil, Russia, India and China. The objective of the project was to study the key factors of entrepreneurial ecosystem that facilitate the growth of knowledge-intensive enterprises in each country. In this paper, we focus on the results obtained for Brazil. We used exploratory factorial analysis and non-hierarchy cluster K-means as methods in order to reach the research objectives. From the analysis of the results, three groups of entrepreneurs with distinct profiles emerged. The data also revealed that the social elements are more important than the personal issues and public policies have an essential role in the development and maintenance of the entrepreneurial ecosystem in Brazil. As limitations, we consider that the low quantity of entrepreneurs can jeopardize the generalization of the findings. Therefore, the replication of this research and the performing of cross-cultural studies are presented as suggestions for future research. Besides, new concepts of Brazilian entrepreneurs based on a quantitative analysis constitute the originality of this study.

\section{Introduction}

In the current capitalist society small sized enterprises have been calling policy makers' attention. This is due to their role in generating jobs and innovating activities, which is becoming increasingly important (Audrestch, 2001; La Rovere, 2001). Such factor leads to a growing number of authors addressing the entrepreneurship issue (Estrin et al., 2013). Although the interest in entrepreneurs has increased in the last decades, the literature has been dealing with the topic for a long time (Simpeh, 2011). Indeed, Schumpeter (1934) was one of the first authors to discuss the phenomenon of entrepreneurship substantially, revealing entrepreneurs as agents of social transformation that create new productive combinations, moving economy towards its growth.

Thus, in developing countries such as Brazil, where entrepreneurship grows at high levels (CPS/FGV, 2010), the importance of these actors is revealed in the impacts of the productive and competitive trajectory, that impact different 
sectors and the economy as a whole. In the Brazilian case, such entrepreneurship expansion is mainly due to the growth of the middle class and the purchasing capacity of this class, which provided the internal market growth and consequently the creation of new business opportunities. Understanding how entrepreneurs find easy ways for their development in an environment like the Brazilian one can provide suggestions to policies guidelines towards those agents.

Thus, the entrepreneur, defined as an agent who transforms the social context, by creating new and innovative business (Labrianidis, 2006) often does not depend only on his/her personal entrepreneurial characteristics and his/her efforts to achieve projects and goals, but is also influenced by environmental variables of the most diverse social spheres. Yet, the success of the entrepreneurs in their functions will be influenced by generation and accumulation of knowledge in their enterprise and by other elements such as: i) the form of competition in the industry where their company is located, ii) the sociocultural context and iii) the support of the government.

Hence, in line with the theoretical studies reported in the literature, this article aims to analyze the profile of the Brazilian entrepreneur, as well as the main factors that contribute for the structuring of the national entrepreneurial ecosystem. Moreover, it aims to know how such factors may be discussed in the Brazilian context, which types of entrepreneurs are found in the country and their main features, and what is the correlation between the factors that cause entrepreneurial action and the profiles of entrepreneurs.

To do so, we conducted a survey with 76 Brazilian entrepreneurs. The research is part of a project involving universities from five countries, called "Entrepreneurship as a Growth Driver: A study of key elements of the entrepreneurial ecosystem enabling, supporting, and harnessing the growth of Knowledge Intensive Entrepreneurship in the ICT sector across BRIC Countries". The project's overall objective was to analyze the key factors of the business ecosystem that facilitate the growth of critical business knowledge in each country and specific objectives: i) to identify and measure the levels of importance of general key factors that facilitate entrepreneurs in business knowledge-intensive; ii) to characterize the formation of different groups of entrepreneurs based on the importance they attach to the general key factors that facilitate the critical business knowledge and iii) to characterize the differences between groups of trained entrepreneurs.

This work is organized in four sections besides the introduction. First of all, we introduce a brief review of related studies about entrepreneurship; after that, we introduce the main methodological aspects, and finally we assess the results and present the final considerations and recommendations for future research.

\section{Entrepreneurship and Entrepreneur Environment}

Entrepreneurship is a multifaceted phenomenon, defined through different meanings (Pato \& Teixeira, 2013). Schumpeter (1934) was one of the first authors to contribute meaningfully to the development of the theory on this subject. The entrepreneur, according to Schumpeter is fundamental to economic development as he or she creates innovations that allow companies to grow and face competition in the market. The entrepreneur is an individual who innovates and creates new combinations, becoming an economic and social agent. However, entrepreneurship is not only connected to the idea of creation of new products or services, but also to adding new ideas and subversive concepts to the context in which the entrepreneur is located (in his home, his city or even in his country), breaking paradigms and opening the horizons of communities (Zahra et al., 2009). The entrepreneur, can be an idealizer of new business (Labrianidis, 2006), besides developing an idea, the or she foresees an opportunity of attainment and transform it in a new product or service, introducing innovations and taking risks (Estrin et al., 2013). Innovation can be in the managing, selling, producing, or distributing products or services, adding additional value to the company.

Entrepreneurship is a tool not only for economic growth but for social development as well, because it transforms the local scenario through innovation, besides making the economy more dynamic. Likewise, entrepreneurship is a cultural, collective and consequently, a community phenomenon. (Mair, \& Marti, 2009; Mair et al., 2012; Estrin et al., 2013). It is the

Revista de Negócios, v. 20, n. 4, p. 30-43, October, 2015. 
community that creates the proper environment for the development of new entrepreneurs. Therefore, a community creates the entrepreneurs it deserves.

About two thirds of the employees in Brazil are in formal micro or small enterprises, so we emphasize the importance of such enterprises for Brazil's economic development (SEBRAE, 2011). However, the statement about the strong tendency of micro entrepreneurs towards bankruptcy is true. According to data raised by SEBRAE (2013), although $73 \%$ of micro enterprises survive the two first years, small enterprises (less than 100 employees) are the ones that file more bankruptcy requests in Brazil. While some are successful in getting support, most of them fail, because often the entrepreneurs that wish to create a new business have only technical knowledge about the product and the decisive factors to its production, but they do not have any knowledge about the importance of managerial tools and the business concept itself. Yet, according to SEBRAE, managerial failures are the main motivation factors to request bankruptcy, followed by problems related to the economic situation, to operational logistics and to difficulties related to public policies.

Indeed, without support, the entrepreneur is almost like a ship without sails drifting in a sea of uncertainties. Therefore, it is judicious to the public institution to support creation and development of enterprises as well as to diffuse opportunities for entrepreneurship (Banerjee, \& Duflo, 2011; Estrin et al., 2013). The government activity, translated into support and follow up of the entrepreneurial activity, helps expansion and maintenance of the entrepreneurs' ecosystem, according to Estrin et al. (2013). However, the authors notice that government actions can harm the development of the entrepreneur activity in case of introducing centralized and authoritarian practices, like usually happens in Latin America and African countries; in the same way, the variables linked to the social contexts also have an important influence on the enterprises. Although government actions are indispensable, we highlight how important it is for the entrepreneurs to have straightforward knowledge of their own business, which is a decisive condition for the success of a small business. The self-knowledge is the basis for the guidance and control of the business and the cornerstone for the business improvement.

According to Pato and Teixeira (2013), another factor that influences entrepreneurship, though not as an externality, is the personal traits of entrepreneurs, as suggested by Casson (2003). According to this author, the individual entrepreneurs' characteristics, including particular demographic and psychological traits, would be responsible for forming the attitude with which such agents act in society, influencing how they make decisions, and whether they would take risks to invest in innovative projects. Demographic traits, among which are the age, gender and place of origin of the entrepreneur, influence entrepreneurship in different ways. Psychological traits emphasized by the literature are duration of education, personal values and passions, entrepreneur's motivations, desire for autonomy, money, challenge or adventure (Gladwin et al., 1989), and aiming at an entrepreneurial life style (Marcketti et al., 2006).

There is a number of theories that try to expalin entrepreneurship (Simpeh, 2011). Among those, psychological theories stand out by studying the locus of control, achievement needs and the disposition for risk taking (Korunka et al. 2003; Simpeh, 2011). Locus control is the entrepreneurs' ability to view and control actions that permeate their life. The necessity of achievement is treated as leadership power, ability to understand the risks and desire to get the best possible performance. Disposition to risk taking depends on the entrepreneurs' knowledge and ability to self-knowledge to assess the context (Reimers-Hils et al., 2005).

Korunka et al. (2003) state that in order to be successful in their business, entrepreneurs must have an internal locus of control, a high need for achievement and an average disposition to risktaking. Câmara et al. (2006) after performing a research in the Brazilian informal market, observed that, opposite to what suggested Korunka et al. (2003): to these authors, entrepreneurs have external loci of control, which means that for them their business destination does not depend on them and their actions will vary according to changes in the environment.

La Rovere and Melo (2012), in a fundamental work for the construction of this research, approached entrepreneurship through seven dimensions of analysis in order to briefly 
assert the characteristics shared by Brazilian entrepreneurs. In their research, connected to the project Entrepreneurship as a Growth Driver, the scale used was based on the following factors: individual characteristics; sociocultural context; government policies and programs; access to finance; access to information, knowledge, opportunities and building skills; companies' internationalization; and factors of success and failure of the business. These factors were identified by Manimala (2008a, 2008b) as the most important to analyze and explain the creation of new businesses and their performance.

Although the subject of entrepreneurship is widely discussed in the literature, there is no single theoretical framework regarding studies related to this topic in the Brazilian scenario. On one hand, several authors emphasize the psychological aspects to entrepreneurs' individual characteristics. On the other hand, other authors emphasize the importance of institutions, public policies and social context for entrepreneurial activity.

This article follows the steps of neoinstitutionalist theory, in which the institutional context explains the decisions taken by entrepreneurs. Therefore, the article aims to contribute to the debate on the topic of entrepreneurship, by offering a brief discussion of the profile of Brazilian entrepreneurs and the main aspects and conditions of entrepreneurial activity.

\section{Methodology}

To meet the research purposes, we undertook an exploratory-descriptive study, with a quantitative nature, carried out by a single crosssectional study, which achievement was obtained by applying a survey (Hair et al., 2009; Malhotra, 2006).

The survey instrument is divided into two sections. The first section consists of 33 variables in 3-point scale, ranging from weak to strong. The scale used in this study is part of a pioneering project on entrepreneurship in different cultures. The project "Entrepreneurship as a Growth Driver" involved five universities, one from each of the BRIC countries (Brazil, India, Russia and China) and was led by the University of Milano Bicocca, Italy. The study proposed to use an ecosystem model to collect information on the factors that enable the growth of companies in the ICT sector, listed in Table 1.

In the second section we raised information about the companies that answered the questionnaire such as: age, ICT activity sector, sales range, employees' number etc.

In Brazil, we sent the questionnaires in September 2011 and 98 questionnaires were completed and returned in February 2012. After a process of validation of the questionnaires and information checking we came to the total of 76 answers. We performed statistical analysis using the Statistical Package for Social Sciences software (SPSS), which was used as descriptive statistics modules, factor analysis, statistical kmeans, multiple discriminant analysis, and oneway ANOVA.

Exploratory factor analysis was performed to identify and measure the levels of importance of the key factors that enable entrepreneurs in intensive business knowledge. The k-means is a non-hierarchical clustering method that performs the separation into groups; the technique was used to characterize the formation of different groups of entrepreneurs based on the importance they attribute to the general key factors that enable the creation of knowledge-intensive enterprises. Finally, ANOVA was used to characterize the differences among the groups of entrepreneurs.

Table 1. Questionnaires

\begin{tabular}{|c|l|c|}
\hline $\mathbf{N}^{\mathbf{0}}$ & \multicolumn{1}{|c|}{ VARIABLE } & CONSTRUCT \\
\hline 1. & Ability to recognize start-up opportunities & $\begin{array}{c}\text { Individual and } \\
\text { Personal } \\
\text { Characteristics }\end{array}$ \\
\hline 2. & Ability to risk taking & \\
\hline 3. & Ability to organize required resources to a start-up & Sociocultural \\
\hline 4. & Presence of family-based entrepreneurship in your society & \\
\hline
\end{tabular}

Revista de Negócios, v. 20, n. 4, p. 30-43, October, 2015. 


\begin{tabular}{|c|c|c|}
\hline 5. & $\begin{array}{l}\text { Culture of promotion and creation of new business and risk taking in the } \\
\text { community }\end{array}$ & Context \\
\hline 6. & Culture of support to creativity and innovation & \\
\hline 7. & Entrepreneurship connected to the idea of desirable careers in the community & \\
\hline 8. & Opportunities for the creation of new businesses & \\
\hline 9. & Opportunities for the creation of new businesses related to gender & \\
\hline 10. & Opportunities for creating new businesses for young people & \\
\hline 11. & Special policies and programs of encouragement and support to start-ups & \multirow{5}{*}{$\begin{array}{l}\text { Support and Public } \\
\text { Policies Program }\end{array}$} \\
\hline 12. & Favorable public policies in general & \\
\hline 13. & Favorable tax policies (special treatment in respect to taxes and fees) & \\
\hline 14. & Easy access to obtain licenses to start a business & \\
\hline 15. & Quality of physical infrastructure, ICT and transport & \\
\hline 16. & Availability of government funds & \multirow{5}{*}{$\begin{array}{l}\text { Access to } \\
\text { Financing }\end{array}$} \\
\hline 17. & Availability of resources of friends and family & \\
\hline 18. & Availability of venture capital funds & \\
\hline 19. & Availability of private funds or angel investors & \\
\hline 20. & Availability of bank loans & \\
\hline 21. & Favorable educational system to entrepreneurship & \multirow{8}{*}{$\begin{array}{l}\text { Access to } \\
\text { Information, } \\
\text { Opportunities to } \\
\text { Knowledge and } \\
\text { Qualification }\end{array}$} \\
\hline 22. & Availability of formal training in entrepreneurial practices & \\
\hline 23. & Assistance and advice to start-ups in colleges and universities & \\
\hline 24. & Support of business associations for membership and networking & \\
\hline 25. & Access to incubators and technology parks & \\
\hline 26. & $\begin{array}{l}\text { Assistance from universities and research institutes for development and } \\
\text { technology transfer }\end{array}$ & \\
\hline 27. & Specific support programs to provide products and services to start-ups & \\
\hline 28. & $\begin{array}{l}\text { Opportunities for collaboration between public and private sectors to enter into } \\
\text { new business }\end{array}$ & \\
\hline 29. & Attitude towards internationalization & \multirow{5}{*}{$\begin{array}{c}\text { Internationalization } \\
\text { of Small and } \\
\text { Medium-Sized } \\
\text { Enteprises }\end{array}$} \\
\hline 30. & Access to information and required qualifications for internationalization & \\
\hline 31. & $\begin{array}{l}\text { Government enabling entry of new firms in new markets (domestic and } \\
\text { international) }\end{array}$ & \\
\hline 32. & Access to financial resources to deal with internationalization & \\
\hline 33. & Access to expertise in foreign languages in the home country & \\
\hline
\end{tabular}

Source: Authors

Revista de Negócios, v. 20, n. 4, p. 30-43, October, 2015. 


\section{Analysis of the results}

Considering that our objective is to analyze the key factors of the entrepreneurial ecosystem that enables knowledge-intensive enterprises, we analyzed the results of the survey, divided in the four following steps.

\subsection{Descriptive Analysis of the Variables}

The descriptive analysis of the survey can be observed on Table 1. From its results, we can notice that Brazilian entrepreneurs have strong individual and personal towards entrepreneurship characteristics, highlighting that $67.1 \%$ have strong ability to recognize start-up opportunities.

Table 1. Descriptive analysis of the variables

\begin{tabular}{|c|c|c|c|c|c|c|c|c|c|c|c|c|c|c|}
\hline $\mathbf{F}$ & $\mathbf{Q}$ & $\begin{array}{c}\text { Item } 1 \\
(\%)\end{array}$ & $\begin{array}{c}\text { Item } 2 \\
(\%)\end{array}$ & $\begin{array}{c}\text { Item } 3 \\
(\%)\end{array}$ & $\mathbf{F}$ & $\mathbf{Q}$ & $\begin{array}{c}\text { Item } 1 \\
(\%)\end{array}$ & $\begin{array}{c}\text { Item } 2 \\
(\%)\end{array}$ & $\begin{array}{c}\text { Item } 3 \\
(\%)\end{array}$ & $\mathbf{F}$ & Q & $\begin{array}{c}\text { Item } 1 \\
(\%)\end{array}$ & $\begin{array}{c}\text { Item } 2 \\
(\%)\end{array}$ & $\begin{array}{c}\text { Item } 3 \\
(\%)\end{array}$ \\
\hline & Q.1 & 2,6 & 30,3 & 67,1 & \multirow{4}{*}{3} & Q.12 & 30,3 & 55,3 & 14,5 & \multirow{6}{*}{5} & Q.23 & 25 & 56,6 & 18,4 \\
\hline 1 & Q.2 & 21,1 & 48,7 & 30,3 & & Q.13 & 44,7 & 35,5 & 19,7 & & Q.24 & 15,8 & 64,5 & 19,7 \\
\hline & Q.3 & 18,4 & 44,7 & 36,8 & & Q.14 & 43,4 & 46,1 & 10,5 & & Q.25 & 23,7 & 56,6 & 19,7 \\
\hline \multirow{7}{*}{2} & Q.4 & 3,9 & 27,6 & 68,4 & & Q.15 & 19,7 & 67,1 & 13,2 & & Q.26 & 31,6 & 52,6 & 15,8 \\
\hline & Q.5 & 3,9 & 44,7 & 51,3 & \multirow{5}{*}{4} & Q.16 & 35,5 & 53,9 & 10,5 & & Q.27 & 36,8 & 56,6 & 6,6 \\
\hline & Q.6 & 18,4 & 38,2 & 43,4 & & Q.17 & 34,2 & 53,9 & 11,8 & & Q.28 & 50,0 & 40,8 & 9,2 \\
\hline & Q.7 & 18,4 & 47,4 & 34,2 & & Q.18 & 36,8 & 56,5 & 6,6 & \multirow{5}{*}{6} & Q.29 & 52,6 & 35,5 & 11,8 \\
\hline & Q.8 & 6,6 & 44,7 & 48,7 & & Q.19 & 32,9 & 52,6 & 14,5 & & Q.30 & 50,0 & 35,5 & 11,8 \\
\hline & Q.9 & 14,5 & 44,7 & 48,7 & & Q.20 & 21,1 & 55,3 & 23,7 & & Q.31 & 52,6 & 38,2 & 9,2 \\
\hline & Q.10 & 18,4 & 47,4 & 34,2 & \multirow{2}{*}{5} & Q.21 & 32,9 & 56,6 & 10,5 & & Q.32 & 64,5 & 31,6 & 3,9 \\
\hline 3 & Q.11 & 27,6 & 57,9 & 14,5 & & Q.22 & 28,9 & 53,9 & 17,1 & & Q.33 & 26,3 & 47,4 & 3,9 \\
\hline
\end{tabular}

Source: Authors

The sociocultural analysis pointed that entrepreneurs see Brazil as favorable to large enterprises and most of them (68.4\%) see the presence of family-based entrepreneurship in their society. Regarding the support programs from public policies, the interviewees do not see such aspect as something strong in the Brazilian context, reaching the number of $44.7 \%$ that do not believe there is a tax policy favorable to entrepreneurship. The access to financing was evaluated as having medium importance by the majority of people who answered the questionnaire.

The interviewees evaluated Brazil with reasonable access to information, knowledge opportunity and qualification. Regarding collaboration opportunities among the public and private sectors, $50 \%$ of the entrepreneurs who answered the questionnaire did not evaluate it well. In the same way, the internationalization of small and medium sized enterprises was badly evaluated in the big majority of its constituting variables. The incentives to the creation of business by women were considered medium for $57.9 \%$ and $31.6 \%$ analyzed it as weak.

We performed an exploratory factor analysis aiming at observing how the variables were grouped. Indeed, the scale showed some inadequacy, due to the analysis of the anti-image matrix, questions Q.2, Q.4 and Q.5 did not obtain absolute values higher than 0.5 (Hair et al., 2009); so, the variables were excluded from the analysis. In a similar way, the variables Q.21 and Q.33 were excluded from the analysis because they presented low common grounds, less than 0.5 (Hair et al., 2009). By doing so, we could proceed with a new exploratory factor analysis.

Thus, one can infer that the ability to take risks (Q.2) is not important in the formation of Brazilian entrepreneurs, the presence of familybased entrepreneurship in the society (Q.4) also does not affect Brazilian entrepreneurs and they do not observe culture of promotion and creation of new business and risk taking in the community 
(Q.5). This shows that entrepreneurs do not like to take risks and business environments are not influencers in a citizen's entrepreneurial training; refuting the concepts addressed by Korunka et al. (2003) that the entrepreneur must have an average risk disposition. Q.21 and Q.33 variables show the weakness that Brazilian educational system has on entrepreneurs' training: it does not help with a favorable education and does not support learning of foreign languages. The lack of training in foreign languages prevents the insertion of enterprises in external markets.

\subsection{General Factors that Make Intensive Knowledge Easy in Knowledge}

We continued by using the method of main components analysis, through orthogonal varimax rotation and the criterion of higher self-values in one (Hair et al., 2009), we obtained eight factors that, as a group, explain $8.91 \%$ of the total variance. As for the KMO (0.727) and Bartlett's sphericity test $(\mathrm{p}=0.000)$, we reached satisfactory values.

Concerning reliability, only the Cronbach alpha referring to factor 7 did not point to satisfaction (0.462), since it did not reach a value higher value than 0,6 (Malhotra, 2006). The other constructs reached values considered satisfactory. (Hair et al., 2009): F1 - 0.848; F2 - 0.755; F3 0.794 ; F4 - 0.735; F5 - 0.773; F6 - 0.672. We did not measure, on the other hand, the reliability of factor 8 , as the construct consists of only one question. So, based on the results obtained, we only excluded factor 8 of future analysis; although construct 7 does not meet the reliability requirements, we decided to keep it due to its theoretical explanation capacity. See table 2 .

By examining the first factor, evidenced on table 2 , we can notice that almost all variables that constitute the original construct, that is access to information, opportunities to knowledge and qualification have grouped, while questions Q.21, Q.22 and Q.24 did not due to their exclusion. Thus we approached as much as possible of denominating the factor to the initial construct, originating the latent variable access to information and to knowledge and other resources. It is important to highlight, though, that there was a small alteration in the original name of the construct, once the variable Q.16 (availability of government funds) has also adhered to the factor. However, although Q.11 has grouped to the factor, the name of the construct was not changed due to its approach to the question and to the other questions. Besides, due to the high explained variance, $26.99 \%$, reached by the factor, we highlight the relevance of the construct for the analysis, bearing in mind it represents more than one third of the total explained by the structure built by the factor analysis.

From this result, it is important to stress that access to information, knowledge and other resources is the main characteristic observed by Brazilians entrepreneurs. However, to Brazilians, the variables: Favorable educational system to entrepreneurship (Q.21); Formal training availability in entrepreneurial practices (Q.22); and support of business associations for membership and networking (Q.24), are not seeing as ways of knowledge and qualification, with the last two ones grouping to form a new factor, training in entrepreneurship and business association (factor 6). However, entrepreneurs observe special policies and programs of encouragement and support to start-ups (Q.11) and availability of government funds (Q.16) along with Q.23, Q.25, Q.26, Q. 27 and Q.28 variables as tools to better skill, knowledge and obtaining resources.

Likewise, the second factor is formed by all variables of the construct internationalization of small and medium-sized enterprises. Therefore, the construct is named in the same way. It should be noted, moreover, that the factor explains $9.71 \%$ of the total variance, positioning itself as the second most important construct of the analysis. The variable access to expertise in foreign languages in the home country (Q.33) was not included in this factor showing that entrepreneurs do not see this issue as a strong trait in Brazil and that it does not explain the internationalization of small and medium-sized Enterprises. In the same way, the third factor, support programs and public policies, consists of all variables that made up the original construct. Thus, the same name was maintained. By observing the variance explained by the factor, it appears that the construct reaches the value of $7.47 \%$, standing as the third most important construct of analysis.

On the other hand, different from the constructs mentioned above, in which almost all variables adhered to their original factors, the fourth originated latent variable is not formed by

Revista de Negócios, v. 20, n. 4, p. 30-43, October, 2015. 
all its initial variables, besides having a variable arising from a different factor. From this construct, we notice that the original one, sociocultural context does not influence the entrepreneurs by itself, being all fragmented in different constructs, revealing that our context only has influence in certain cases. In this case, context influences the variables ability to recognize start-up opportunities (Q.1); opportunities for the creation of new businesses
(Q.8); opportunities for the creation of new businesses related to gender (Q.9); and opportunities for creating new businesses for young people (Q.10), showing that there are entrepreneurs that have abilities to recognize business opportunities in Brazil. This way, from the analysis of the questions' statements comprising it variables, we named the fourth factor, ability to recognize business opportunities.

Table 2. Factors

\begin{tabular}{|c|c|c|c|c|}
\hline Factor & Variables & $\begin{array}{l}\text { Factorial } \\
\text { Loadings }\end{array}$ & $\begin{array}{c}\text { Explained } \\
\text { Variance }(\%)\end{array}$ & Construct \\
\hline \multirow{7}{*}{ Factor 1} & Q. 11 & 0.627 & \multirow{7}{*}{26.998} & \multirow{7}{*}{ Access to Information, Knowledge, and other Resources } \\
\hline & Q. 16 & 0.473 & & \\
\hline & Q. 23 & 0.750 & & \\
\hline & Q. 25 & 0.528 & & \\
\hline & Q. 26 & 0.819 & & \\
\hline & Q. 27 & 0.755 & & \\
\hline & Q. 28 & 0.620 & & \\
\hline \multirow{4}{*}{ Factor 2} & Q. 29 & 0.729 & \multirow{4}{*}{9.714} & \multirow{4}{*}{ SMEs Internationalization } \\
\hline & Q. 30 & 0.790 & & \\
\hline & Q. 31 & 0.614 & & \\
\hline & Q. 32 & 0.547 & & \\
\hline \multirow{4}{*}{ Factor 3} & Q. 12 & 0.549 & \multirow{4}{*}{7.474} & \multirow{4}{*}{ Support and Public Polices Programs } \\
\hline & Q. 13 & 0.711 & & \\
\hline & Q. 14 & 0.701 & & \\
\hline & Q. 15 & 0.673 & & \\
\hline \multirow{4}{*}{ Factor 4} & Q. 1 & 0.538 & \multirow{4}{*}{5.968} & \multirow{4}{*}{ Ability to Recognize Business Opportunities } \\
\hline & Q. 8 & 0.742 & & \\
\hline & Q. 9 & 0.840 & & \\
\hline & Q. 10 & 0.679 & & \\
\hline \multirow{3}{*}{ Factor 5} & Q. 3 & 0.768 & \multirow{3}{*}{5.427} & \multirow{3}{*}{ Culture of Support and Ability of Organization } \\
\hline & Q. 6 & 0.693 & & \\
\hline & Q. 7 & 0.781 & & \\
\hline \multirow{2}{*}{ Factor 6} & Q. 22 & 0.667 & \multirow{2}{*}{5.136} & \multirow{2}{*}{ Entrepreneurship Training and Business Association } \\
\hline & Q. 24 & 0.793 & & \\
\hline \multirow{3}{*}{ Factor 7} & Q. 17 & 0.629 & \multirow{3}{*}{4.494} & \multirow{3}{*}{ Access to Informal Private Funding } \\
\hline & Q. 18 & 0.604 & & \\
\hline & Q. 19 & 0.625 & & \\
\hline Factor 8 & Q. 20 & 0.827 & 3.707 & Access to Bank Funding \\
\hline
\end{tabular}

Source: Authors

In a comparable way, we named factor 5 as culture of support and organization ability, because this comprises two other sociocultural variables and one individual characteristic: ability to organize required resources to a start-up (factor $3)$; culture of support to creativity and innovation (Q.6); entrepreneurship connected to the idea of desirable careers in the community (Q.7). So we may consider Brazilians as organized entrepreneurs that have the intention to build up a career while helping their communities.

The other constructs were named according to the relationship between their variables, obtaining the following names: factor 6 - training in entrepreneurship and business association (already addressed in previous paragraphs); factor 7 - access to informal private 
funding, this factor was formed by the variable availability of resources of friends and family (Q.17); availability of venture capital funds (Q.18); availability of private funds or angel investors (Q.19). We observe from this factor that Brazilians do not see the availability of government funds (Q.16) as a way of financing and analyze the availability of bank loans as an isolated factor that forms factor 8 . Even if this factor has $3.7 \%$ of the explained variance, it becomes important because it is a unique form of financing that Brazilians use little but know it is available. A plausible explanation for the unsuitability of these two variables with each other to form a single factor of access to finance is the difficulties to get financing.

From the point of view of the entrepreneur's locus of control, it is clear that Brazilian entrepreneurs in knowledge-intensive sectors attribute significant importance to external factors (external locus of control), which explains the failure to form a factor with the variables related to their profile as entrepreneurs and the importance given to the factor of access to information and knowledge. It seems that the entrepreneurs studied do not value their individual skills, their success probably is strongly attributed to environmental and external issues.

Such perception goes against propositions by Korunka et al. (2003), concerning the ideal training of entrepreneurs. For the authors the ideal entrepreneur must have an internal locus of control, while the results show that Brazilians have, in contrast, external loci of control; confirming the research by Câmara et al. (2006).

\subsection{Entrepreneur Groups}

Proceeding with the analysis, the k-means statistical technique was conducted as a way to investigate the quantity of different groups originated. It is worth noting that for the analysis, we used only the first seven factors, due to the fact that the eighth factor presents only one question. Therefore, through this method, three clusters emerged. By forcing the analysis with a larger number of groups we did not observe an increase in the difference of variance among them, obtained through the tests results of ANOVA, which reveals meaningful differences among the groups in almost all the eight variables raised in the factor analysis. The values reached in the test can be visualized on Table 3 .

Concerning the results visualized on Table 3 , regardless of test $\mathrm{F}$ results evidenced by $\mathrm{K}$ means should be used only for descriptive purposes, we highlight that only in factor 6 the difference in variance of clusters was not verified, which indicates there is no meaningful difference among the groups observing the variable training in entrepreneurship and business association.

To the validation of the solution with three clusters, raised by the analysis, we performed a multiple discriminating analysis. The results obtained indicate that $97.5 \%$ of the original grouped cases were correctly classified. Besides, $90.8 \%$ of the grouped cases by crossed validation were correctly classified. The results show that there is, in fact, a rigorous outline among groups emerged in the analysis.

By examining the group factor loadings separately, pointed on Table 4, we notice that the first cluster, comprised of $35.5 \%$ of the total sample (27), includes people who answered the questionnaire whose factor loadings reached positive values only in factor 1: access to information, knowledge and other resources; while all other factors reached negative value, or very close to zero. Thus, we named the group Learners, since its entrepreneurs stand out for the importance of access to information and to knowledge.

Similarly, the second cluster, consisting of $27.6 \%$ of all people who answered the questionnaire (21), includes people who answered the questionnaire who obtained average positive factor loadings on factors 4,6 and 7, respectively: ability to recognize business opportunities; training in entrepreneurship and business association and; access to informal private financing; moreover, all other factors had negative average. Based on the proposed measurement of positively received constructs, the group received the name of Attentive Collaborators because they seek cooperation, but they are aware of business opportunities and availability of funding to take better advantage of such opportunities.

Finally, the third cluster, representing $36.8 \%$ of the sample (28), include people who answered the questionnaire who achieved average positive factor loadings on factors $2,3,5$, respectively, of small and medium-sized enterprises internationalization support programs and public policies, and culture support and

Revista de Negócios, v. 20, n. 4, p. 30-43, October, 2015. 
organization skills; while all other factors had negative or near zero indexes. According to the evaluation of the constructs that directly influence its formation, the cluster was named Dependent
Competitors because they compete in the international market, but they consider public policies and culture of support as relevant.

Table 3. ANOVA test between the factors (K means statistic)

\begin{tabular}{|c|c|c|c|c|c|c|}
\hline & \multicolumn{2}{|c|}{ Cluster } & \multicolumn{2}{|c|}{ Error } & \multirow{2}{*}{ Teste F } & \multirow{2}{*}{ Sig. } \\
\hline & Mean Square & df & Mean Square & df & & \\
\hline Factor 1 & 14.506 & 2 & 0.630 & 73 & 23.025 & $0.000 * * *$ \\
\hline Factor 2 & 5.190 & 2 & 0.885 & 73 & 5.863 & $0.004 * * *$ \\
\hline Factor 3 & 3.669 & 2 & 0.927 & 73 & 3.958 & $0.023^{* *}$ \\
\hline Factor 4 & 5.472 & 2 & 0.877 & 73 & 6.237 & $0.003 * * *$ \\
\hline Factor 5 & 9.746 & 2 & 0.760 & 73 & 12.817 & $0.000 * * *$ \\
\hline Factor 6 & 0.623 & 2 & 1.010 & 73 & 0.616 & 0.543 \\
\hline Factor 7 & 8.778 & 2 & 0.787 & 73 & 11.155 & $0.000 * * *$ \\
\hline Factor 8 & & & Do not Analys & & & \\
\hline
\end{tabular}

** Significant at $5 \%$

*** Significant at $1 \%$

Source: Authors

In this way, the groups were named, according to their main characteristics: Learners, Attentive Collaborators, and Dependent Competitors. Such classification shows there is a certain diversity of types of entrepreneurs in Brazil and intensive sectors knowledge, it also reveals that entrepreneurs have predominantly external loci of control, but in different directions; confirming, once again, the results found by Câmara et al. (2006).

Table 4. Factorial loadings between groups

\begin{tabular}{|c|c|c|c|c|c|c|c|c|}
\hline & & Factor 1 & Factor 2 & Factor 3 & Factor 4 & Factor 5 & Factor 6 & Factor 7 \\
\hline \multicolumn{2}{|c|}{ Quantity } & 27 & 27 & 27 & 27 & 27 & 27 & 27 \\
\hline Mean & Group 1 & 0.7666 & -0.2097 & -0.2904 & -0.5873 & -0.1648 & -0.0207 & 0.0481 \\
\hline \multicolumn{2}{|c|}{ Quantity } & 21 & 21 & 21 & 21 & 21 & 21 & 21 \\
\hline Mean & Group 2 & -0.6075 & -0.0963 & -0.3631 & 0.6755 & -0.5023 & 0.1465 & 0.6380 \\
\hline \multicolumn{2}{|c|}{ Quantity } & 28 & 28 & 28 & 28 & 28 & 28 & 28 \\
\hline Mean & Group 3 & -0.2836 & 0.2745 & 0.5523 & 0.0597 & 0.5357 & -0.0898 & -0.5249 \\
\hline
\end{tabular}

4.4 Differences among the Entrepreneur Groups

Consequently, we performed ANOVA tests among the clusters originated by the analysis using each factor in an isolated way; visualized on Table 5 and on Graph 1. Thus, as it is possible to notice on Table 5, cluster 1 - Learners - had meaningful difference in variance as compared to other groups, fixing factor 1 - access to information, to knowledge, and other resources as parameter; which would make the group identity stronger, since it is characterized as the only group to reveal positively the scanned factor. In a similar way, the cluster also presented a meaningful variance compared to other two groups when we analyzed factors 4 and 7 . 
Similarly, as it is possible to notice on Table 5, by using factor 2 as parameter of analysis, results showed that there are differences among the variances obtained by the clusters 1 and 3 - Dependent Competitors; in confidence interval of $10 \%$. The same procedure was performed using factors 3 and 5 as dependent variable. The results contribute to the importance of factor 1 to the conceptual formation of cluster 3 , revealing the fundamental importance of the two factors for the formation of individual identities classified as Dependent Competitors. The group, besides, showed differences in the variance compared to other clusters when factor 7 was analyzed.

Fixing factor 4 as dependent, on the other hand, the second cluster - Attentive Collaborators - presented meaningful differences in the variable when analyzed with the other groups. Although the other groups have also demonstrated significant differences in the variance, we highlight the importance of such factor to build the conceptual framework of the cluster, observed through the analysis of factor loadings examining factor 4. In the same way, we repeated the procedure using factors 6 and 7 as dependent variables. Even though when we examine factor 6 there is no difference in the variance between groups, indicating that the factor is not characterized as a different barrier for the construction of the cluster, when we fix factor 7 as a dependent variable, the Attentive Collaborators group presented differences in variance compared to the other groups; it is worth noting that we also verified differences among the remaining groups.

Table 5. ANOVA between clusters

\begin{tabular}{|c|c|c|c|c|}
\hline & & Cluster 1 & Cluster 2 & Clusters 1, 2 e 3 \\
\hline \multirow{2}{*}{ Factor 1} & Cluster 2 & $32.916 * * *$ & - & \multirow{2}{*}{$19.222 * * *$} \\
\hline & Cluster 3 & $20.687 * * *$ & 2.096 & \\
\hline \multirow{2}{*}{ Factor 2} & Cluster 2 & 0.171 & - & \multirow{2}{*}{1.782} \\
\hline & Cluster 3 & $3.082 *$ & 1.662 & \\
\hline \multirow{2}{*}{ Factor 3} & Cluster 2 & 0.093 & - & \multirow{2}{*}{$8.07 * * *$} \\
\hline & Cluster 3 & $9.672 * * *$ & $12.280 * * *$ & \\
\hline \multirow{2}{*}{ Factor 4} & Cluster 2 & $25.564 * * *$ & - & \multirow{2}{*}{$12.380 * * *$} \\
\hline & Cluster 3 & $6.414 * *$ & $6.998 * *$ & \\
\hline \multirow{2}{*}{ Factor 5} & Cluster 2 & 1.411 & - & \multirow{2}{*}{$8.429 * * *$} \\
\hline & Cluster 3 & $9.615 * * *$ & $14.897 * * *$ & \\
\hline \multirow{2}{*}{ Factor 6} & Cluster 2 & 0.333 & - & \multirow{2}{*}{0.338} \\
\hline & Cluster 3 & 0.061 & 0.660 & \\
\hline \multirow{2}{*}{ Factor 7} & Cluster 2 & $5.475 * *$ & - & \multirow{2}{*}{$10.156^{* * *}$} \\
\hline & Cluster 3 & $5.49 * *$ & $19.431 * * *$ & \\
\hline
\end{tabular}

Source: Authors

Based on the analysis of the variables and constructs that constitute the groups that emerged in the research, we observe that people who answered the questionnaire named Learners are entrepreneurs that search more actively for the intellectual improvement connected to business activity. The Learners share the same objective concerning the expansion of the theoretical contribution that would support the business opening, in the expansion of control both in the business operational activities and in the search of new opportunities. Although the intellectual dimension comes strongly for the conceptual explanation of the group, we highlight the importance of obtaining resources for the cluster. Therefore, the fact that the cluster Learners has emerged from the analysis reveals the importance of investing in entrepreneurship education, as well as in offering mechanisms that provide entrepreneurs the chance to climb higher levels in the business trail, such as incubators, subsidies, consultancy and legal advice. 
Similarly, we observe that Attentive Collaborators entrepreneurs demonstrate an ability to recognize business opportunities meaningfully different from other groups of entrepreneurs; they also search for improvement of the skills required to today's entrepreneur, as well as the expansion of business through the implementation of partnerships and associations. Another important factor for Attentive Collaborators is access to informal private funding, indicating that the search group for parallel sources of funds, which probably incur lower interest and damages to the business. Such results reveal the bold and impassive nature of these entrepreneurs facing the perception of new business opportunities or in the management of their companies.
Finally, examining the variables statements that characterize the entrepreneurs belonging to the third cluster, we can notice that individuals classified as Dependent Competitors have a strong inclination to expand their business. Entrepreneurs in this group search for expanding the influence of their companies, once the construct Internationalization of Small and Medium-sized Enterprises emerged as a seminal factor to the theoretical framework of the group, relying on subsidies and public policy programs. Such results suggest that Dependent Competitors make good research on infrastructure, tax policy, and public and social environment to support entrepreneurship for the opening and expansion of their businesses.

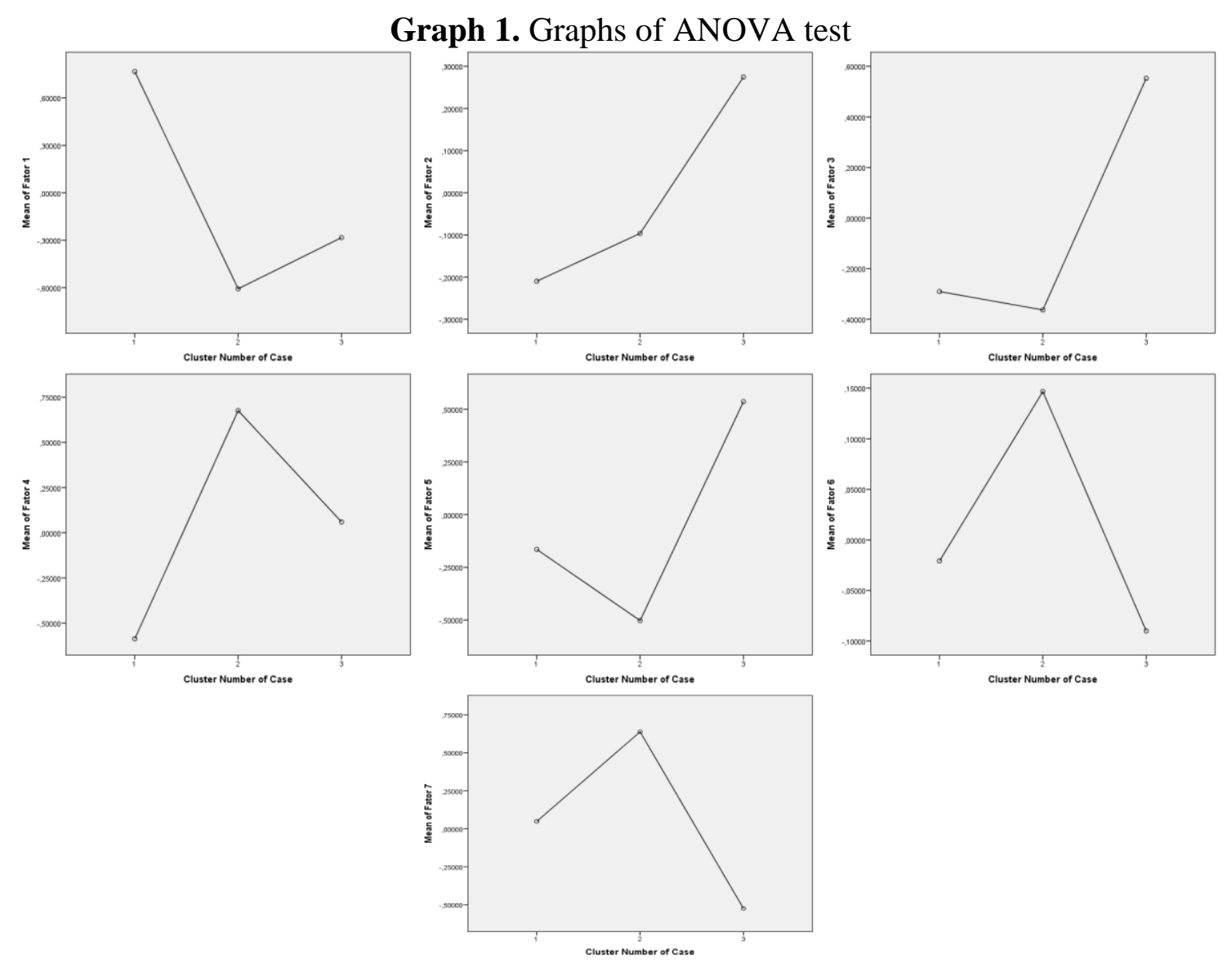

Source: Authors

As we can observe by analyzing the constructs making up the groups formed in all clusters the factor of government support emerges. Whether in the form of monetary support, such as funding and resources, or as incentives to professional qualification and access to training, education and business skills, public policies play an essential role in the development of local entrepreneurship. Thus, although other dimensions were also considered relevant by our research, the distinct contribution of Government in the conceptual construction of the groups, highlights the research by Câmara et al. (2006) according to which Brazilian entrepreneurs have external loci of control.

\section{Conclusion}

Revista de Negócios, v. 20, n. 4, p. 30-43, October, 2015. 
We reached our general and specific objectives in the article when: i) we identified and measured the levels of importance of general key factors that enables entrepreneurs in knowledgeintensive enterprises; ii) we characterized the formation of three different groups of entrepreneurs based on the importance they attribute to the general key factors that enable the knowledge critical to enterprises and iii) characterized the differences among the three groups that emerged from the analysis.

Therefore, we can conclude that Brazilian entrepreneurs in the studied sector, have strong external loci of control and in general show great importance to access to information and knowledge, which was expected due to the characteristics of the sector analyzed. The culture of developing countries possibly accounts for the assignment of success to external conditions in detriment of personal values and efforts.

Data analysis also revealed the formation of a typology of three distinct groups, which explain the possible subtle differences among the entrepreneurs' groups. In this case, the following groups stood out, namely: i) focused on learning and knowledge accumulation; ii) having probably more opportunities of strategies and collaboration at the same time, which seems contradictory, but there is a vast literature that meets the competition with collaboration as a business success strategy, and last; iii) entrepreneurs with strong competitive bias and international perspectives, but, who, at the same time value the policies and culture of support. Thus, three dimensions of external dependence for the studied entrepreneurs were revealed: i) dependence on knowledge; ii) dependence on collaboration and favorable markets and iii) dependence on public policies and culture of support to entrepreneurs.

Considering the three dimensions revealed, we can conclude that the strategies for the stimulus and promotion of entrepreneurship in Brazil should go through public policies that: i) encourage assimilation and generation of growth ii) stimulate the collaboration between entrepreneurs and e iii) provide access to financial resources and expand networks of support of entrepreneurs.

It is important to remark that the study has some limitations. First of all, we researched only 76 entrepreneurs, an extremely low number that affect the generalization of the inferred results. It is also important to add that the research was not based on a probabilistic sample.

As a suggestion to future research, we indicate the replication of the used scale used in this study so that its validity is verified. In the same way, we suggest the expansion of the analysis concerning the entrepreneur's profiles. The theory on entrepreneurship in Brazil needs more conceptual contributions about the core and restrict characteristics of entrepreneurs that act in Brazil. In the same way, cross-cultural researches that compare Brazilian entrepreneurs' profiles with other nations are valid as tools for benchmarking and proposition of support policies.

\section{References}

Audrestch, D. (2001). Research Issues Relating to Structure, Competition and Performance of Technology-Based Firms. Small Business Economics, 16, 37-51.

Banerjee, A., \& Duflo, E. (2011). Poor economics: A radical rethinking of the way to fight global poverty. New York: Public Affairs.

Câmara, S. F. et al. (2006). Os empreendedores e as atividades organizacionais: Analisando o processo cognitivo e as práticas administrativas em pequenos negócios. Revista de Práticas Administrativas, 2(6), 67-76.

Casson, M. (2003). The EntrepreneurAn Economic Theory. 2nd Edition. Cheltenham, UK: Edward Elgar.

CPS/FGV. (2010). A Nova Classe Média: o Lado Brilhante dos Pobres. Rio de Janeiro, RJ, 2010. Acesso em: www.fgv.br/cps.

Estrin, S. et al. (2013). Entrepreneurship, Social Capital, and Institutions: Social and Commercial Entrepreneurship Across Nations. Entrepreneurship Theory and Practice, May, 479504.

Gladwin, C. H. et al. (1989). Rural entrepreneurship: one key to rural revitalization. American Journal of Agricultural Economics, 71(5), 1305-1314.

Hair, J. F. et al. (2009). Análise Multivariada de Dados. $6^{\mathrm{a}}$ ed. Porto Alegre: Bookman.

Korunka, C. et al. (2003). The entrepreneurial personality in the context of resources, environment, and the startup process A configurational approach. Entrepreneurship Theory and Practice, 28(1), 23-42. 
La Rovere, R. L. (2001). Perspectivas das Micro, Pequenas e Médias Empresas no Brasil. Revista de Economia Contemporânea, 5, Edição Especial, 20-38.

La Rovere, R. L., \& Melo, L. J. S. (2012). A profile of ICT Entrepreneurs in Brazil. Proceedings of International Conference on Information Resources Management, Viena, Austria.

Labrianidis, L. (2006). Fostering entrepreneurship as a means to overcome barriers to development of rural peripheral areas in Europe. European Planning Studies, 14(1), p. 3-8.

Mair, J., \& Marti, I. (2009).

Entrepreneurship in and around institutional voids: a case study from Bangladesh. Journal of Business Venturing, 24, 419-435.

Mair, J. et al. (2012). Building inclusive markets in rural Bangladesh: How intermediaries work institutional voids. Academy of Management Journal, 55(4), 2012, 819-850.

Malhotra, N. K. (2006). Pesquisa de marketing: uma orientação aplicada. $6^{\mathrm{a}}$ ed., Porto Alegre: Bookman.

Manimala, M. (2008a) Entrepreneurship Education in India: an assessment of SME training needs against current practices. International Journal Entrepreneurship and Innovation Management, 6, 624-647.

Manimala, M. (2008b). Evolution of the Bangalore Cluster: a Stage Theory Based on Crystal Growth Model Carayannis. In: E. G. \& Formica, P. (eds). Knowledge matters: technology, innovation and entrepreneurship in innovation networks and knowledge clusters. Basingstoke (UK)/New York: Palgrave Macmillan, 4-128.

Marcketti, S. B. (2006). An Exploratory Study of Lifestyle Entrepreneurship and Its Relationship to Life Quality. Family and Consumer Sciences Research Journal, 34(241), 241-259.

Pato, L. M., \& Teixeira, A. C. (2013). Twenty Years of Rural Entrepreneurship: A Bibliometric Survey. FEP Working Papers, (516), $1-32$.

Reimers-Hild, C. I. et al. (2005). A Framework for the "Entrepreneurial" Learner of the 21st Century. Online Journal of Distance Learning Administration, 8(2), 2005.

Schumpeter, J. (1934). Theory of economic development: an inquiry into profits, capital, credit, interest and the business cycle. Cambridge: Havard University Press.

Serviço Brasileiro de Apoio às Micro e Pequenas Empresas (2011). Taxa de Sobrevivência das Empresas no Brasil. São Paulo, SP. Acesso em: http://www.sebrae.com.br/.

Serviço Brasileiro de Apoio às Micro e Pequenas Empresas (2013). Sobrevivência das Empresas no Brasil. São Paulo, SP. Acesso em: http://www.sebrae.com.br/.

Simpeh, K. N. (2011). Entrepreneurship theories and Empirical research: A Summary Review of the Literature. European Journal of Business and Management, 3(6), 1-9.

Zahra, S. A. et al. (2009). A typology of social entrepreneurs: Motives, search processes and ethical challenges. Journal of Business Venturing, 24(5), 519-532.

Revista de Negócios, v. 20, n. 4, p. 30-43, October, 2015. 